\title{
The Relationship Between Internalized Homophobia and Intimate Partner Violence in Same-Sex Relationships: A Meta-Analysis
}

TRAUMA, VIOLENCE, \& ABUSE

2019, Vol. 20(3) 33I-343

(C) The Author(s) 2017

Article reuse guidelines:

sagepub.com/journals-permissions

DOI: $10.1177 / \mid 52483801770878$

journals.sagepub.com/home/tva

(A) SAGE

\author{
Laura Badenes-Ribera', Julio Sánchez-Meca², and Claudio Longobardi ${ }^{3}$
}

\begin{abstract}
A meta-analysis was conducted to investigate the association between internalized homophobia and intimate partner violence (IPV) perpetration and victimization in same-sex relationships. The literature search and the application of the inclusion criteria made it possible to identify 10 studies, 2 of which were excluded due to missing data. Therefore, eight studies were finally included in the meta-analysis. The results showed positive and statistically significant associations between internalized homophobia and IPV perpetration and victimization, indicating that higher levels of internalized homophobia were related to higher levels of IPV. Specifically, the pooled effect size for the relationship between internalized homophobia and IPV perpetration (all forms), it was $r_{+}=.147,95 \%$ confidence interval $(\mathrm{Cl})=[.079, .214]$; for the association between internalized homophobia and physical/sexual IPV perpetration, it was $r_{+}=.166,95 \% \mathrm{Cl}[.109, .221] ; p<.0001$; for the relationship between internalized homophobia and psychological IPV perpetration, it was $r_{+}=.145,95 \% \mathrm{Cl}[.073, .216]$; and for the association between internalized homophobia and any type of IPV victimization, it was $r_{+}=.102,95 \% \mathrm{Cl}[.030, .173]$. Implications of these results for clinical practice and future research are discussed.
\end{abstract}

\section{Keywords}

intimate partner violence, internalized homophobia, same-sex partner, meta-analysis

Intimate partner violence (IPV) is a significant public health problem that affects at least one in three women in the United States in their lifetimes (Black et al., 2011). Recently, researchers have begun to examine IPV experiences among lesbian women, gay men, bisexual individuals, transsexual individuals, and queer people (LGBTQ). These studies have documented that rates of IPV in lesbian, gay, and bisexual (LGB) individuals are equal to or even greater than rates observed in heterosexual individuals (Ard \& Makadon, 2011; Badenes-Ribera, Bonilla-Campos, Frias-Navarro, Pons-Salvador, \& Monterdei-Bort, 2016; Edwards, Sylaska, \& Neal, 2015; Finneran \& Stephenson, 2013; Goldberg \& Meyer, 2013; Hellemans, Loeys, Buysse, Dewaele, \& De Smet, 2015; Nowinski \& Bowen, 2012; Walters, Chen, \& Breiding, 2013). Furthermore, risk factors for IPV in LGB individuals have shown some similarities with IPV in heterosexual individuals, but they have also included unique factors, such as those related to their sexual minority identity, which may help to explain higher IPV rates in LGB individuals (Badenes-Ribera et al., 2016; Chong, Mak, Mabel, \& Kwong, 2013; Edward et al., 2015; Lewis, Milletich, Kelley, \& Woody, 2012; Mason et al., 2014).

Minority stress theory (DiPlacido, 1998; Meyer, 2003) is a model that examines the unique, chronic, and socially based factors affecting stigmatized minorities. According to Meyer (2003), the underlying assumptions of the minority stress concept are that minority stress is (a) unique, which means that it is in addition to general stressors that are experienced by all people, and thus, stigmatized individuals are required to make an adaptation effort beyond that of other similar individuals who are not stigmatized; (b) chronic, which means that minority stress is associated with relatively stable underlying cultural and social structures; and (c) socially based, which means that minority stress arises from social processes, institutions, and structures beyond the individual, rather than individual events or conditions. Therefore, minority stress is defined as "the excess stress to which individuals belonging to stigmatized social categories are exposed, by effect of their minority social standing" (Meyer, 2003, p. 675). Consequently, minority stress is a form of psychosocial stress derived from being a member of a stigmatized and marginalized minority group. Moreover,

\footnotetext{
'Department of Methodology of the Behavioral Sciences, University of Valencia, Valencia, Spain

${ }^{2}$ University of Murcia, Murcia, Spain

${ }^{3}$ University of Turin, Turin, Italy

Corresponding Author:

Laura Badenes-Ribera, Department of Methodology of the Behavioral Sciences, University of Valencia, Avda. Blasco lbáñez, 21. 46010 Valencia, Spain.

Email: laura.badenes@uv.es
} 
individuals who belong to more than one minority group experience additional stress (e.g., lesbian women).

The minority stress model makes the distinction between internal and external stressors. The internalized factors include stressors such as the degree of outness or closetedness, perceived discrimination or stigma consciousness (the extent to which the members of a minority group expect to be stereotyped by others and experience discrimination; Pinel, 1999), and internalized homophobia. External stressors include experiences of violence, discrimination, and harassment.

Internalized homophobia is defined as the degree to which individuals belonging to a sexual minority have internalized negative feelings, attitudes, beliefs, behaviors, and assumptions about their homosexuality (Balsam, 2001; Rostosky, Riggle, Gray, \& Hatton, 2007). Several studies have suggested that internalized homophobia could be associated with violent behavior against members of one's own group (Renzetti, 1988) because negative assumptions about homosexuality are integrated into an individual's identity (West, 2012). Therefore, individuals with negative feelings about their LGB identities might engage in violence against their own partners. Furthermore, LGB people who believe that they are somehow defective may think they deserve to be treated abusively and, consequently, see the abuse as a natural consequence of their LGB identity, whereas a perpetrator might use his or her partner's internalized homophobia to justify his or her own violence (Balsam, 2001).

The literature has shown a relationship between internalized homophobia and IPV perpetration and victimization (Balsam \& Szymanski, 2005; Edwards \& Sylaska, 2013; Finneran, Chard, Sineath, Sullivan, \& Stephenson, 2012; Finneran \& Stephenson, 2014; Kelley et al., 2014; Milletich, Gumienny, Kelley, \& D'Lima, 2014; Peeper \& Sand, 2015; Roberts, 2006; West, 2012). For example, Finneran and Stephenson (2014) found that internalized homophobia was associated with the perpetration of sexual IPV in men who have sex with men. Nevertheless, this association between internalized homophobia and IPV is not consistent across studies (Bartholomew, Regan, Oram, \& White, 2008; Carvalho, Lewis, Derlega, Winstead, \& Viggiano, 2011; Chong et al., 2013; McKenry, Serovich, Mason, \& Mosack, 2006; Pepper \& Sand, 2015).

The aim of the current study was to perform a meta-analysis of all the available studies about IPV in same-sex relationships and internalized homophobia, in order to determine whether internalized homophobia increases the risk of IPV perpetration or victimization in same-sex relationships.

\section{Method}

\section{Study Selection Criteria}

In order to be included in the meta-analysis, the studies had to fulfill the following criteria:(1) they had to be published from 2005 to 2015, both included, in a peer-reviewed journal; (2) the article had to describe an original, quantitative study; (3) the study had to empirically examine the relationship between internalized homophobia and IPV in same-sex relationships; (4) participants in the study had to be at least 18 years old; (5) the statistical data reported in the study had to allow computation of effect size magnitudes; and (6) due to language limitations, the study had to be written in English, Spanish, or Italian.

Therefore, qualitative studies, literature reviews, systematic reviews, meta-analyses, commentaries, editorials, and studies that did not assess IPV in same-sex relationships and its relationship with internalized homophobia were excluded from this review. In addition, the review did not include studies where minors were participants.

\section{Search Strategy}

First, several electronic databases were consulted: Scopus, Medline, ProQuest, Web of Science, and Google scholar, using the following terms: intimate partner violence, domestic violence, same-sex, gay, lesbian, internalized homophobia, and minority stress. Second, the reference lists of all the studies included previous literature reviews, and relevant studies on IPV were reviewed. Third, a search was conducted manually in eight specialized journals: Psychology of Woman Quarterly, Journal of Homosexuality, Journal of Gay and Lesbian Social Services, Journal of LGBT Issues in Counseling, Journal of Aggression, Maltreatment and Trauma, Journal of Interpersonal Violence, Trauma, Violence and Abuse, and Journal of Family Violence. Furthermore, experts in the field of LGBTQ studies were asked to identify additional studies.

Figure 1 presents a flowchart describing the screening and selection of the studies. The search strategy produced a total of 601 references. Duplicated studies were eliminated $(n=185)$, leaving a total of 416 studies to review.

The selection was performed independently by two researchers. A reconciliation process was undertaken for those studies where there was disagreement. First, the titles and abstracts of the 416 studies were scanned, and the relevant studies were preselected based on the inclusion and exclusion criteria. There were 55 preselected studies. Second, the complete text of each preselected study was reviewed, and 45 studies were excluded for not meeting the inclusion criteria. A total of 10 articles fulfilled the selection criteria, all of them written in English and published in a peer-reviewed journal during the period from 2005 to 2015 . Nevertheless, two articles were excluded from the meta-analysis because they did not report the required statistical data on the association between internalized homophobia and IPV (Mckenry et al., 2006; Peppe \& Sand, 2015). Therefore, eight studies were finally included in the meta-analysis.

\section{Coding of the Studies}

A protocol for extracting the characteristics of the studies was elaborated and applied to each study. The study characteristics coded were as follows: country where the study was carried out, sampling method, mean age of the respondents (in years), 


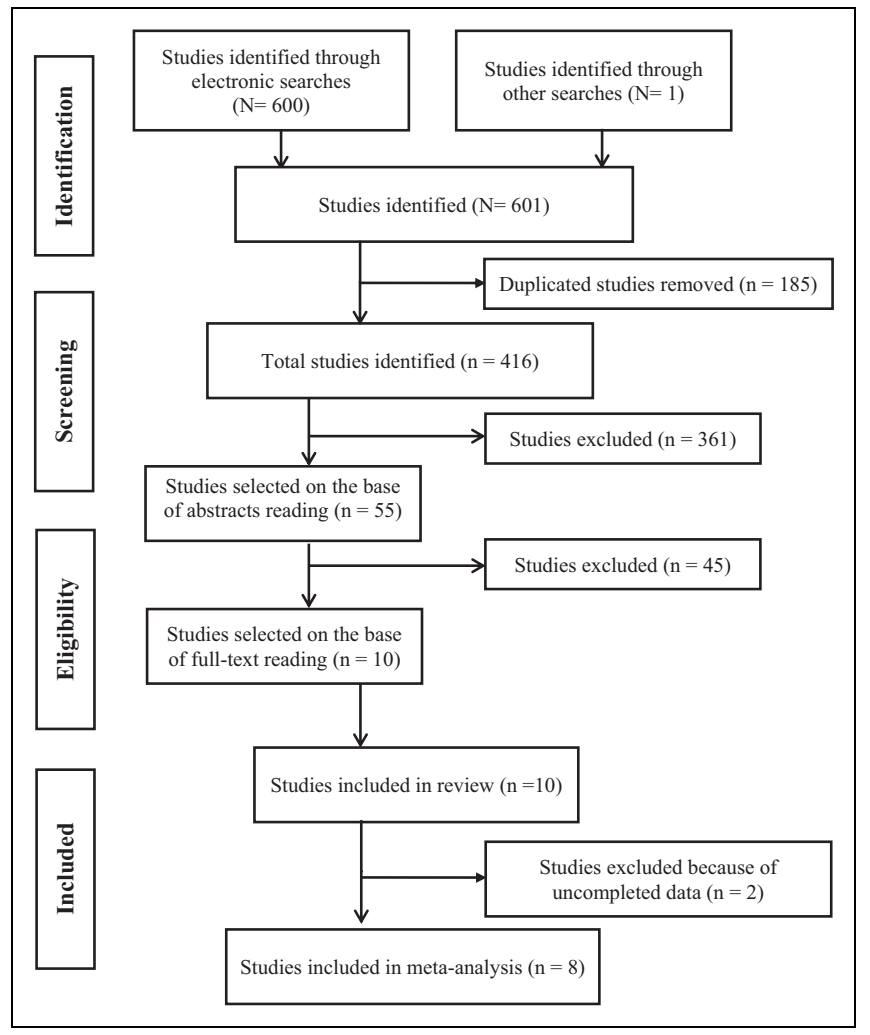

Figure I. Flowchart of the meta-analysis of internalized homophobia and intimate partner violence in same-sex relationships.

ethnic distribution of the sample, education levels of the respondents, scale used to assess IPV, and scale used to assess internalized homophobia. In addition, the methodological quality of the studies was assessed by means of the "Methodological quality rating guide of descriptive studies on same-sex intimate partner violence" developed by Murray and Mobley (2009). This scale is composed of 15 dichotomous items (evaluated as either present or absent): (1) a sampling procedure that ensures a representative sample; (2) specified criteria for eligibility; (3) specified criteria for exclusion; (4) an assessment of sexual orientation (e.g., self-reporting or using a scale designed to measure sexual orientation); (5) appropriate treatment of partners within particular relationships - that is, if partners within the same relationship are either (a) not both included in the same sample or (b) paired in the data analysis; (6) specified timing of data collection; (7) sufficiently detailed description of the methodology to allow replication; (8) sound assessment instrumentation; (9) social desirability control; (10) clarification of the types of abuse measured; (11) definitions of abuse presented; (12) standardized and specified conditions for participation; (13) multiple levels of variables measured; (14) adequate statistical analyses; and (15) appropriate conclusions based on the data collected.

The coding process was carried out in a standardized and systematic way. The data were coded independently by two reviewers. Reliability coefficients were satisfactory, with intraclass correlations ranging from .86 to 1 for continuous variables. For qualitative variables, all $\kappa$ coefficients were equal to
1. Disagreements between the coders were resolved through dialogue.

\section{Computing of Effect Sizes}

The effect size index used in this meta-analysis was the Pearson correlation coefficient calculated between the scale of internalized homophobia and the scale of physical/sexual or psychological IPV used in each study (Borenstein, Hedges, Higgins, \& Rothstein, 2009). To normalize the distribution and stabilize the variance, the Pearson correlations were translated to Fisher's $Z \mathrm{~s}: Z_{r}=\frac{1}{2} \log _{e}\left(\frac{1+r}{1-r}\right)$, with sampling variance: $V\left(Z_{r}\right)=1 /(n-3), n$ being the sample size of the study.

After carrying out the statistical analyses, the Fisher's $Z$ of the individual effect sizes, as well of the mean effect sizes and their confidence limits, was translated back into the Pearson correlation metric to aid their interpretation by means of $r=\frac{\mathrm{e}^{2 Z r}-1}{\mathrm{e}^{2 r_{r}+1}}$, with e being the base of natural logarithms (Borenstein et al., 2009). To simplify the practical interpretation of the effect sizes obtained in the meta-analyses, the guidelines proposed by Cohen (1988) were applied. Following these guidelines, correlation coefficients of about .10, .30, and .50 (in absolute values) can be interpreted as reflecting a low, moderate, and large relationship between the variables. It is worth noting that a correlation equal to .10, although of low magnitude, can still be considered to have practical relevance.

From each study, several correlations could be extracted, one for each meta-analysis resulting from a type of IPV (physical/sexual and psychological IPV) in relation to IPV status (perpetrators and victims). When a study reported several correlations about the same relationship (e.g., between internalized homophobia and psychological IPV), their average was calculated to avoid statistical dependence.

In studies where correlation coefficients were not directly reported, appropriate translations between effect sizes were applied. Thus, in Carvalho, Lewis, Derlega, Winstead, and Viggiano's (2011) study, a standardized mean difference (d) was calculated from the means and standard deviations of two groups and then the $d$ index was translated into a correlation coefficient (Borenstein et al., 2009). To assess the reliability of the effect-size extraction process, two coders extracted them independently. Interrater reliability was quite satisfactory, with intraclass correlations of 1 .

\section{Statistical Analysis}

Separate meta-analyses were carried out with the effect sizes calculated according to the type of IPV (any IPV, psychological IPV, or physical/sexual IPV) and IPV status (perpetrators and victims). To carry out a meta-analysis, at least four studies had to report a correlation between the two constructs (type of IPV and IPV status). To accommodate the variability in the effect sizes, random-effects models were assumed in the meta-analytic calculations. These models assume a genuine diversity in the results of the various studies and incorporate the variance between studies into the calculations. In each 
meta-analysis, a pooled correlation coefficient and its corresponding $95 \%$ CI were calculated. In addition, the statistical significance test for the pooled correlation was assessed using a $Z$ test. Forest plots were constructed to represent the individual and pooled effect size estimates with their $95 \%$ CIs and to allow visual inspection to study heterogeneity. To assess the heterogeneity among the individual effect sizes, both the Cochran's $Q$-statistic and the $I^{2}$ index were calculated (Borenstein et al., 2009; Huedo-Medina, Sánchez-Meca, Marín-Martínez, \& Botella, 2006). When effect sizes are homogeneous, the $Q$-statistic follows a chi-squared distribution with $k-1$ degrees of freedom, with $k$ being the number of studies. A $Q$-statistic with a $p$ value $<.05$ is indicative of heterogeneity among the effect sizes. The degree of heterogeneity was estimated with the $I^{2}$ index, which can be interpreted as the percentage of total variation across the studies due to their different characteristics. $I^{2}$ values around $25 \%, 50 \%$, and $75 \%$ denote low, moderate, and large heterogeneity, respectively. One of the advantages of the $I^{2}$ is that it is not affected by the number of studies considered (Botella \& Sánchez-Meca, 2015; Higgins \& Thompson, 2002; Huedo-Medina et al., 2006).

To assess whether publication bias might be a threat to the validity of the mean effect size, funnel plots were applied using Duval and Tweedie's (2000) trim-and-fill method. When funnel plot asymmetry was observed, effect estimates corrected for small study effects were generated with the trim-and-fill method. This technique uses available data to impute missing (unreported) studies and recalculates the overall effect that would be observed had they been included. In addition, Egger tests were applied. A nonstatistically significant result of the $t$ test for the hypothesis of an intercept equal to zero allows publication bias to be discarded as a threat to the validity of the pooled effect (Sterne \& Egger, 2005).

All statistical tests were interpreted assuming a significance level of $5 \%(\alpha=.05)$, using two-tailed tests. The statistical analyses were carried out with the program Comprehensive Meta-Analysis 3.0 (Borenstein, Hedges, Higgins, \& Rothstein, 2014).

\section{Results}

To carry out a meta-analysis, at least four studies had to report a correlation between the two constructs (type of IPV and IPV status). However, not all the studies reported on the association between internalized homophobia and IPV or one of its forms. Thus, each meta-analysis included a different number of studies, ranging from 4 to 8 .

\section{Descriptive Characteristics and Study Quality}

Table 1 describes the main characteristics of the eight studies included in this review. Six of the studies were carried out in the United States, one was conducted in Canada (Bartholomew et al., 2008), and one in China (Chong et al., 2013). All the studies used nonprobabilistic sampling methods, except the study by Bartholomew, Regan, Oram, and White (2008), which used a probabilistic sample. All the studies applied a crosssectional design, and all participants were volunteers who had been contacted over the telephone or through e-mail, listservs, websites of groups or organizations dedicated to men's or women's issues, pride events, universities, or local libraries. In some cases, the participants were motivated with rewards (Bartholomew et al., 2008; Edwards \& Sylaska, 2013; Kelly et al., 2014; Lewis, Milletich, Derlega, \& Padilla, 2014; Milletich et al., 2014); in other cases, university students earned research credits for their participation (Kelley et al., 2014; Milletich et al., 2014).

The studies' sample sizes ranged from 107 (Kelly et al., 2014) to 581 (Carvalho et al., 2011) participants, with a mean of 284. In seven of the eight studies, the majority of the participants identified themselves as Caucasian, whereas the percentages of other racial and ethnic groups varied; the exception was the study by Chong, Mak, Mabel, and Kwong (2013), where most of the participants were Chinese. The mean age represented in the various samples was about 33.5 years. In addition, most of the participants in each study had received at least some college education. Finally, all participants reported being in a relationship with a same-sex partner at the time of the study or having been in a relationship with a same-sex partner during the previous year.

\section{Assessment of Methodological Quality}

All studies employed validated scales to assess the level of internalized homophobia. Concerning IPV, all studies used validated scales, except the one by Carvalho et al. (2011), which employed its own definition. The assessment instruments most frequently found in the studies were the Internalized Homophobia Scale (Herek, Cogan, Gillis, \& Glunt, 1998), for internalized homophobia, and the Conflict Tactics Scale-Revised Edition (Straus, Hamby, Boney-McCoy, \& Sugarman, 1996) for IPV.

Most of the studies met the following criteria: (1) describe the methodologies employed in sufficient detail to allow replication, (2) measure variables across multiple levels of assessment, (3) employ appropriate statistical analyses, and (4) draw appropriate conclusions based on the empirical evidence. Nevertheless, none of the studies provided data on power analysis. In addition, most of them did not report CIs around the effect sizes measured (e.g., Balsam \& Szymanski, 2005; Bartholomew et al., 2008; Edwards \& Sylaska, 2013).

Finally, the criteria that were least likely to be met by the studies were (1) specifying exclusion criteria, (2) using appropriate strategies to address partners within the same relationship as part of the study samples, (3) specifying the timing of the data collection, and (4) using a strategy to control for social desirability (none of the studies did this). Other criteria also infrequently performed were (5) using representative sampling procedures (e.g., employing a mailing list of a lesbian 


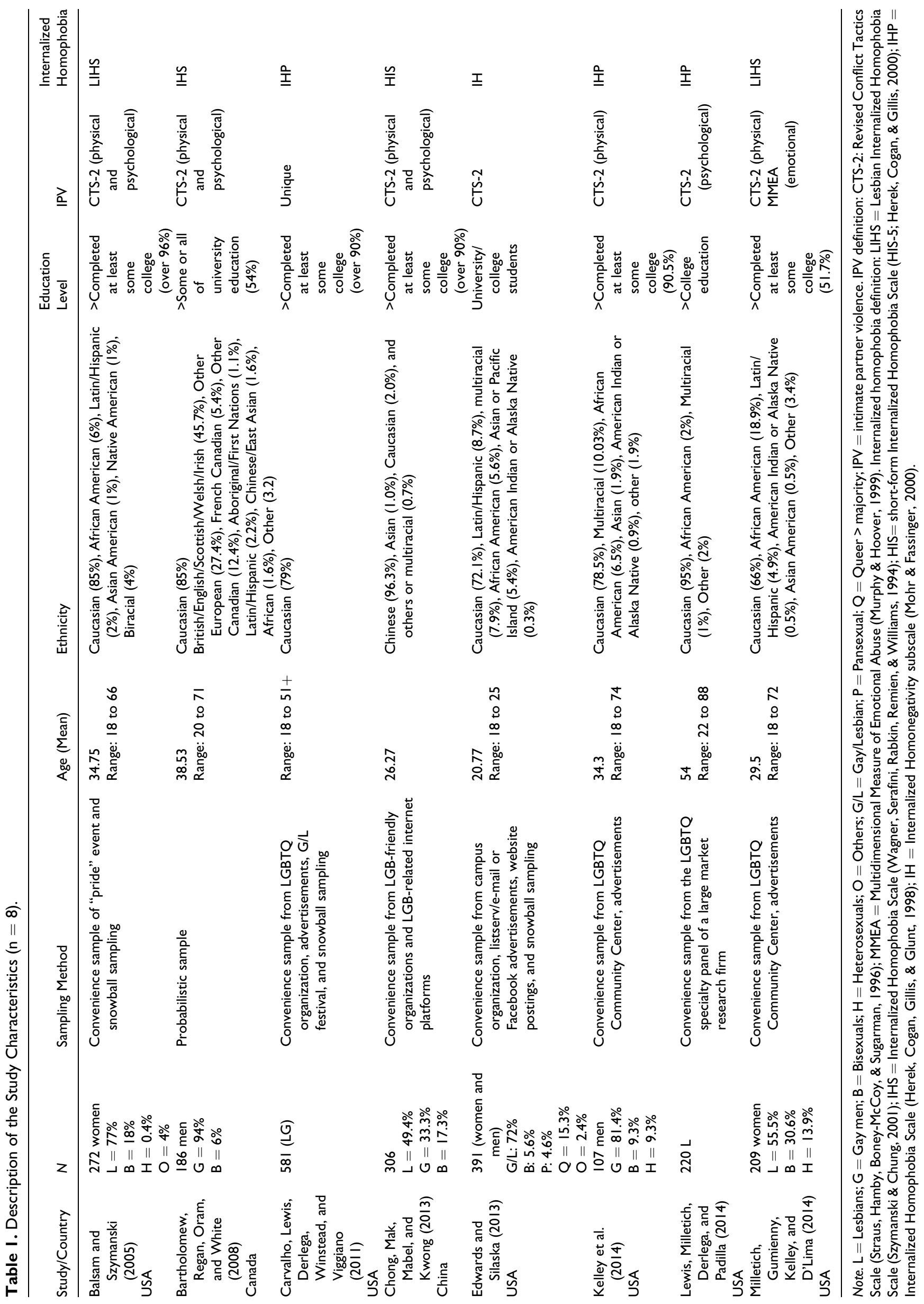




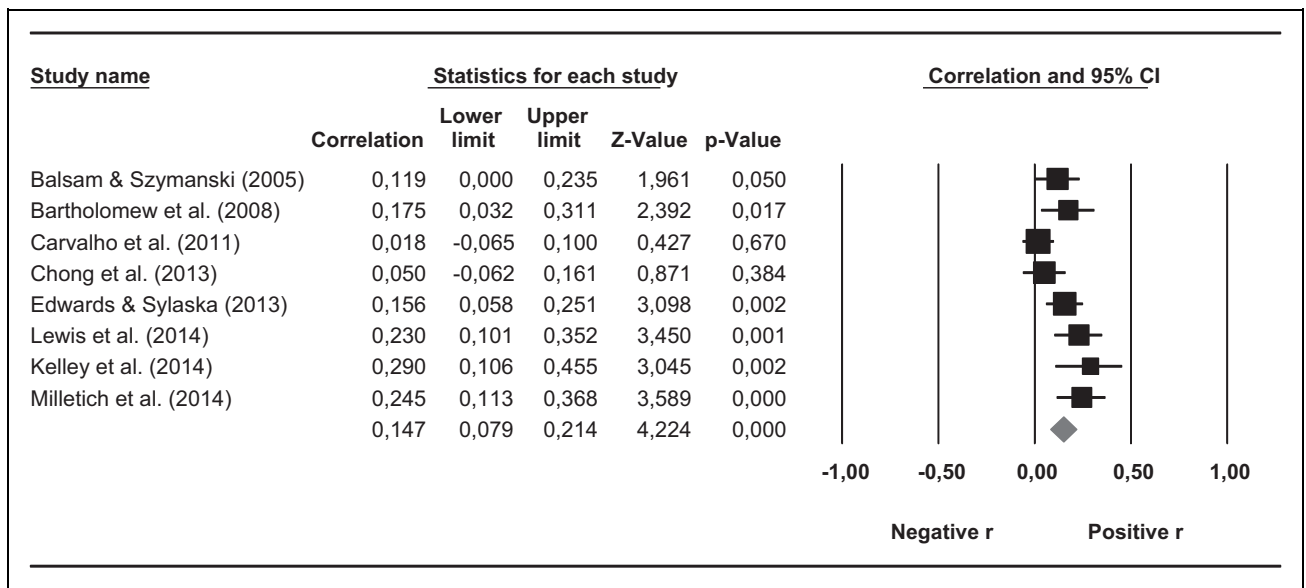

Figure 2. Forest plot of the association between internalized homophobia and any intimate partner violence perpetration.

\begin{tabular}{|c|c|c|c|c|c|c|c|c|c|}
\hline \multirow[t]{2}{*}{ Study name } & \multicolumn{5}{|c|}{ Statistics for each study } & & \multicolumn{3}{|c|}{ Correlation and $95 \% \mathrm{Cl}$} \\
\hline & Correlation & $\begin{array}{c}\text { Lower } \\
\text { limit }\end{array}$ & $\begin{array}{l}\text { Upper } \\
\text { limit }\end{array}$ & Z-Value & $\mathrm{p}$-Value & & & & \\
\hline Balsam \& Szymanski (2005) & 0,144 & 0,026 & 0,259 & 2,378 & 0,017 & & & - & \\
\hline Bartholomew et al. (2008) & 0,190 & 0,047 & 0,325 & 2,602 & 0,009 & & & - & \\
\hline Chong et al. (2013) & 0,060 & $-0,052$ & 0,171 & 1,046 & 0,296 & & & & \\
\hline Edwards \& Sylaska (2013) & 0,185 & 0,087 & 0,279 & 3,687 & 0,000 & & & & \\
\hline Kelley et al. (2014) & 0,290 & 0,106 & 0,455 & 3,045 & 0,002 & & & $\rightarrow-$ & \\
\hline \multirow[t]{4}{*}{ Milletich et al. (2014) } & 0,210 & 0,076 & 0,336 & 3,060 & 0,002 & & & - & \\
\hline & 0,166 & 0,109 & 0,221 & 5,690 & 0,000 & & & & $\mid$ \\
\hline & & & & & & $-1,00$ & $-0,50$ & 0,00 & 1,00 \\
\hline & & & & & & & Negative $r$ & Positive $\mathrm{r}$ & \\
\hline
\end{tabular}

Figure 3. Forest plot of the association between internalized homophobia and physical/sexual intimate partner violence perpetration.

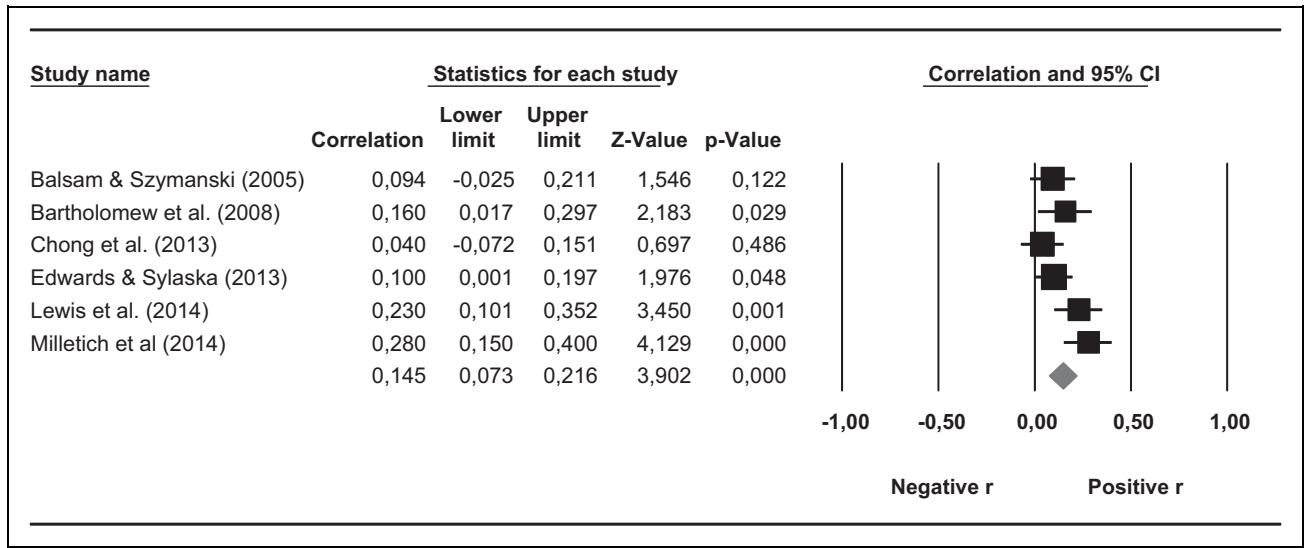

Figure 4. Forest plot of the association between internalized homophobia and psychological intimate partner violence perpetration.

organization, snowball sampling through LGBTQ organizations, or widespread community contacts such as through pride events) and (6) standardizing the conditions for participants' involvement in the research program (the majority of the studies $[n=7]$ performed an online survey, which was not considered to follow standardizing conditions).

\section{The Overall Relationship Between Internalized Homophobia and IPV in Same-Sex Relationships}

To assess the relationship between internalized homophobia and IPV, four separate meta-analyses were conducted. Figures 2-4 show forest plots for each meta-analysis about the 


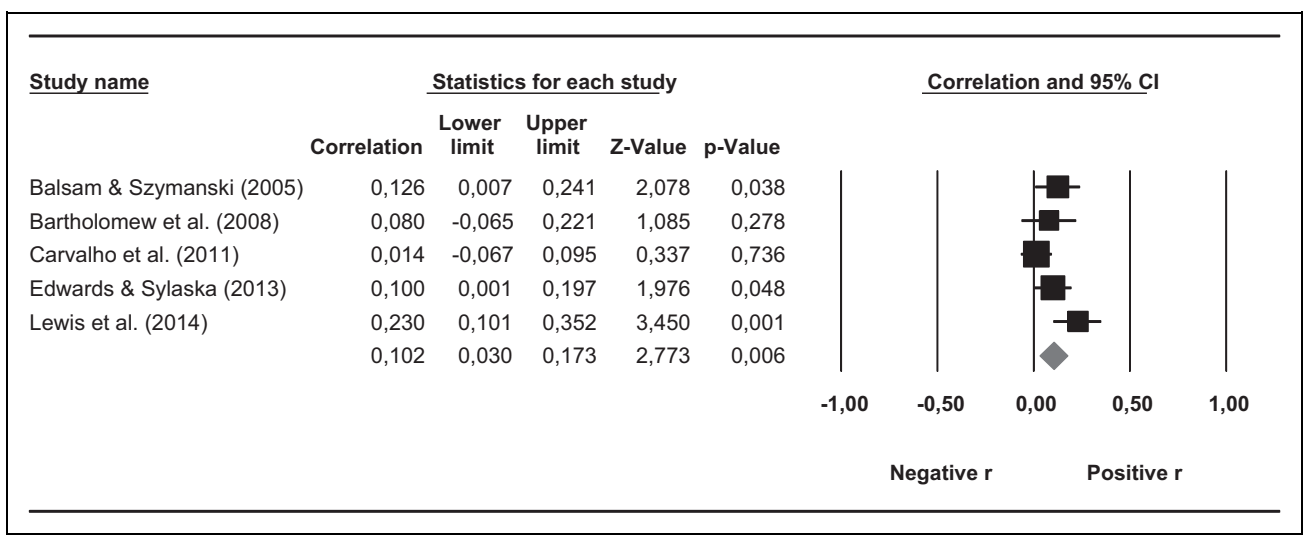

Figure 5. Forest plot of the association between internalized homophobia and any intimate partner violence victimization.

relationships between internalized homophobia and IPV perpetration. Small but significant relationships were found between internalized homophobia and each type of IPV measured (any IPV, physical/sexual IPV, and psychological IPV), indicating that higher levels of internalized homophobia were associated with an increased likelihood of IPV.

As Figure 2 shows, the pooled effect size for the relationship between internalized homophobia and IPV perpetration (all forms) was $r_{+}=.147,95 \%$ CI $[.079, .214] ; p<.0001$, indicating that the greater the internalized homophobia, the greater the IPV perpetration. Following Cohen's (1988) criteria, a correlation coefficient of $r_{+}=.147$ can be interpreted as reflecting a low-medium, but relevant, relationship. In addition, moderate to large heterogeneity among individual effect sizes was found, $Q(7)=17.972, p=.012, \tau^{2}=.006, I^{2}=61 \%$.

Figure 3 presents the forest plot of the relationship between internalized homophobia and physical/sexual IPV perpetration. As Figure 3 shows, the mean effect size for the association between these two variables was $r_{+}=.166,95 \%$ CI [.109, $.221] ; p<.0001$, indicating that the greater the degree of internalized homophobia, the greater the likelihood of physical/sexual IPV perpetration. Following Cohen's (1988) criteria, a correlation coefficient of $r_{+}=.166$ can be interpreted as reflecting a low-medium, but relevant, relationship. Heterogeneity among the effect size estimates in the primary studies was low, $Q(5)=6.104, p=.296, \tau^{2}=.001, I^{2}=18.1 \%$.

The relationship between internalized homophobia and psychological IPV perpetration was also low but statistically significant, as Figure 4 shows: $r_{+}=.145,95 \%$ CI $[.073, .216] ; p<$ .0001 , indicating that higher levels of internalized homophobia were associated with more psychological IPV perpetration. Following Cohen's (1988) criteria, a correlation coefficient of $r_{+}=.145$ can be interpreted as reflecting a low-medium, but relevant, relationship. In addition, heterogeneity among effect size estimates in the primary studies was moderate, $Q(5)=10.697, p=.058, \tau^{2}=.004, I^{2}=53.3 \%$.

Finally, Figure 5 shows the forest plot for the association between internalized homophobia and any type of IPV victimization. A small but statistically significant relationship was found between these two variables: $r_{+}=.102,95 \%$ CI [.030,
$.173] ; p=.006$, indicating that higher levels of internalized homophobia were associated with more likelihood of IPV victimization. Following Cohen's (1988) criteria, a correlation coefficient of $r_{+}=.102$ can be interpreted as reflecting a low, but relevant, relationship. Heterogeneity among effect sizes was moderate, $Q(4)=8.271, p=.082, \tau^{2}=.003, I^{2}=51.6 \%$.

Heterogeneity was evident across all meta-analyses, with $I^{2}$ ranging between $51.6 \%$ and $61 \%$, thus showing heterogeneity among the effect sizes in the outcomes of the primary studies, except in the relationship between internalized homophobia and physical/sexual IPV perpetration, which showed low heterogeneity. Nevertheless, due to the small number of studies, it was not possible to perform an analysis of the study characteristics that might explain the variability in effect sizes.

Publication bias. To assess whether publication bias might be a threat to the validity of the results of our meta-analyses, several graphical and analytic techniques were applied. First, funnel plots were constructed, and the trim-and-fill method proposed by Duval and Tweedie was applied in order to achieve symmetry when they showed an asymmetric pattern. Figure 6 presents the funnel plots with the trim-and-fill method for each meta-analysis. Of the four funnel plots constructed, the trimand-fill method required the imputation of effect sizes in two of them to achieve symmetry. One of these was the funnel plot that showed the association between internalized homophobia and IPV perpetration (all forms). In this case, Duval and Tweedie's method imputed two effect estimates. Nevertheless, the adjusted mean $r\left(r_{+}=.118 ; 95 \%\right.$ CI $\left.[.051, .184]\right)$ showed a slight difference from the original mean $r\left(r_{+}=.147\right)$. The other asymmetrical funnel plot represented the meta-analysis of the relationship between internalized homophobia and physical/sexual IPV perpetration. When Duval and Tweedie's method was applied to this funnel plot, two effect estimates were imputed. In this case, the adjusted mean $r\left(r_{+}=.143\right.$; $95 \%$ CI $[.087, .199])$ showed a negligible difference from the original mean $r\left(r_{+}=.166\right)$.

Egger tests were applied to each of the four meta-analyses as another method to assess publication bias. The Egger test reached statistical significance only for the meta-analysis of 


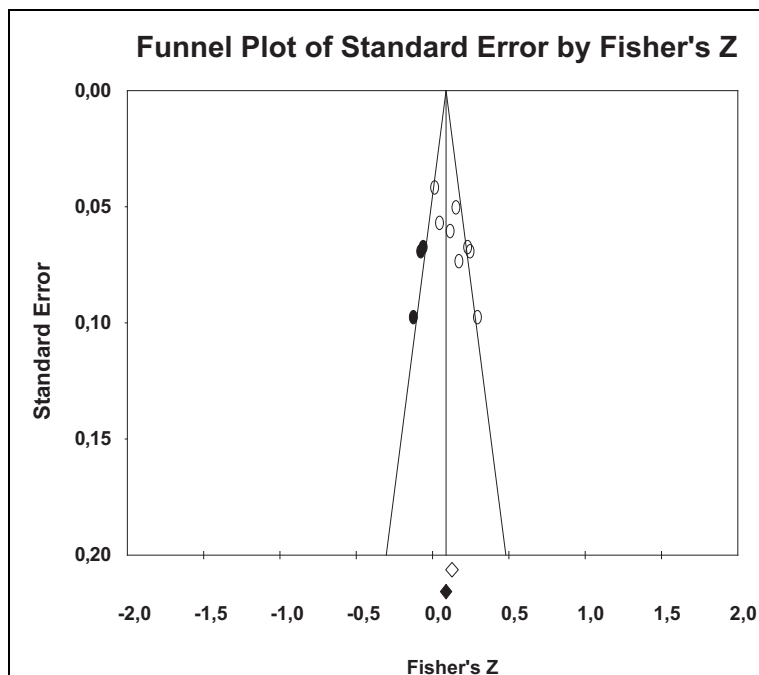

A) IH and Any IPV Perpetration

Funnel Plot of Standard Error by Fisher's Z

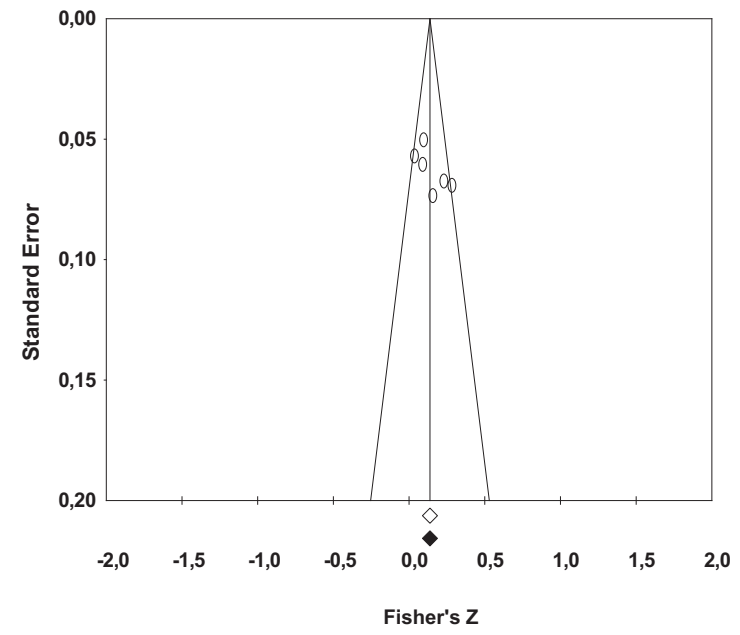

C) IH and PsychologicalPerpetration

\section{Funnel Plot of Standard Error by Fisher's Z}

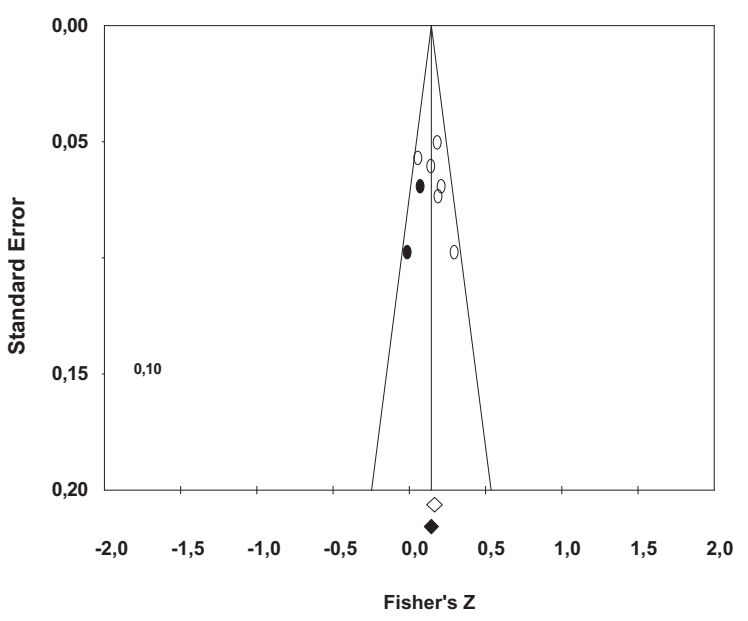

B) IH and Physical/Sexual IPV Perpetration

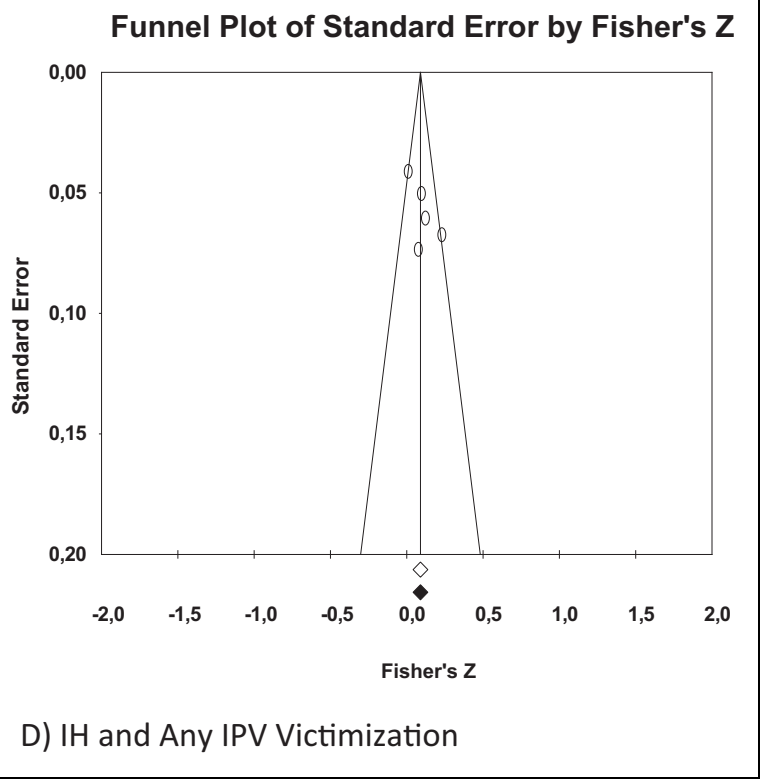

Figure 6. Funnel plots of internalized homophobia $(\mathrm{IH})$ and intimate partner violence in same-sex relationship to assess publication bias. White circles represent each of the included studies. Black circles represent the new effect estimated to achieve symmetry.

the relationship between internalized homophobia and any IPV perpetration $(p=.012)$. Therefore, based on the results of these different analyses, publication bias can reasonably be discarded as a threat to our meta-analytic findings.

\section{Discussion}

To assess the relationship between internalized homophobia and IPV, we conducted four separate meta-analyses on the relationship between internalized homophobia and four other variables: IPV perpetration (all forms), physical/sexual IPV perpetration, psychological IPV perpetration, and internalized homophobia and IPV victimization. We found small associations between internalized homophobia and IPV in the four meta-analyses performed. In this way, the results showed statistically significant positive associations between internalized homophobia and IPV perpetration and between internalized homophobia and IPV victimization, suggesting that higher levels of internalized homophobia were related to more IPV perpetration and victimization. Therefore, on the one hand, LGB people with negative feelings about themselves may project their negative self-concept through violent acts toward their same-sex partners. On the other hand, victims with negative feelings about themselves may believe that they deserve to be treated abusively and see the abuse as a natural consequence of their LGB identity (Stiles-Shields \& Carroll, 2015).

In addition, it is worth noting that the overall association between internalized homophobia and IPV was higher for all 
cases of IPV perpetration than for IPV victimization. Nevertheless, there was an overlap between the CIs for the mean effect sizes of the different meta-analyses.

These findings give empirical support to the role that sexual minority stress theory (Meyer, 2003) can play in understanding IPV in LGBTQ individuals. Prior research has found that stigma consciousness (e.g., expectations of prejudice and discrimination due to being gay or lesbian), degree of outness, and experience of discrimination based on sexual orientation were related positively to IPV in same-sex relationships among LGB people (Bartholomew et al., 2008; Carvalho et al., 2011; Edwards \& Sylaska, 2013; Kelley et al., 2014). For example, stigma consciousness was positively associated with IPV perpetration and victimization in gay men and lesbian women, suggesting that individuals with high levels of stigma are more likely to be involved in violent relationships (Carvalho et al., 2011) and that LGB individuals prefer to keep violence quiet in an effort to protect victims of IPV in same-sex relationships from a homophobic legal system (Carvalho, 2006, quoted in Carvalho et al., 2011). Being more "out" was related to an increased risk of IPV victimization among gay and bisexual men and lesbian women (Bartholomew et al., 2008; Carvalho et al., 2011), and lower levels of disclosure of one's sexual orientation were related to an increased risk of physical IPV perpetration among LGBTQ youth (Edwards \& Sylaska, 2013) and gay and bisexual men (Kelley et al., 2014). Finally, sexual orientation-related discrimination experiences were positively related to the perpetration of psychological same-sex partner violence among LGBTQ youth (Edwards \& Sylaska, 2013). These sexual minority stressors interact with IPV to create or exacerbate vulnerabilities in people experiencing IPV in samesex relationships, and they may also exacerbate the feelings of isolation and helplessness experienced by victims of IPV (Stiles-Shields \& Carroll, 2015).

Nevertheless, it is noteworthy that the relationship between internalized homophobia and IPV may be mediated by the levels of fusion and rumination experienced by relationship partners and by overall relationship quality (Balsam \& Szymanski, 2005; Lewis et al., 2014; Milletich et al., 2014). Fusion is defined as the blurring of boundaries between people who experience a loss of self as individuals (Krestan \& Bepko, 1980). In this context, violence between intimate partners is used to maintain a balance between the degree of separateness or connectedness in a relationship (Bartle \& Rosen, 1994). Therefore, as Milletich, Gumienny, Kelley, and D'Lima (2014) pointed out, partners who perceive that their same-sex partners are too emotionally dependent or independent may resort to violence as a means of regaining a desired level of fusion in the relationship. In this way, verbal and physical violence might be a way for partners who want more independence to express their need to be separate (Lockhart, White, Causby, \& Isaac, 1994; McCandlish, 1982; Miller, Greene, Causby, White, \& Lockhart, 2001; Renzetti, 1988). Nevertheless, this fusion may be an adaptive response to a general lack of social validation and a hostile environment, as same-sex partners may attempt to isolate themselves from the negativity they encounter in heterosexist society by fostering a relatively closed relationship (Greene, Causby, \& Miller, 1999; Lockhart et al., 1994).

Rumination is a general psychological process, an emotion regulation strategy that, according to the literature, is used by members of stigmatized groups to cope with feelings of unworthiness (internalized homophobia) and expectations of rejection by others (stigma consciousness; Lewis et al., 2014). Studies have found that LGB people who have negative feelings about themselves and their sexual identity engage in significantly more rumination and report more psychological distress (Hatzenbuehler, Dovidio, Nolen-Hoeksema, \& Phills, 2009). In addition, rumination has been shown to impair thinking, problem-solving, instrumental behavior, and social relationships (Nolen-Hoeksema, Wisen, \& Lyubominsky, 2008). According to Lewis, Milletich, Derlega, and Padilla (2014), these four effects of rumination may shed light on how this process may serve as a link between internalized homophobia and IPV. For example, rumination may lead to negative thoughts (e.g., self-blame, self-criticism, and pessimism in dealing with sexual minority stressors) and less social support from a partner in the relationship, which, in turn, may cause less satisfaction with the relationship and more IPV. Thus, more research is needed to improve our understanding of the factors that might mediate or moderate the relationship between minority stressors and IPV in same-sex relationships (Edwards \& Sylaska, 2013).

On the other hand, given the heterosexist social context in which same-sex partner violence occurs, victims and perpetrators of IPV may not receive adequate attention from the healthcare system, the police, or the courts. For example, LGB people may be marginalized by those from whom they seek help (Badenes-Ribera et al., 2016; Bernstein \& Kostelac, 2002; Brown, 2008; Peterman \& Dixon, 2003). Consequently, there is a need for education and training programs in same-sex couples partner violence for service providers who do not specifically serve LGBTQ people. This training might ensure the necessary services for LGBTQ people who are victims of partner violence and avoid secondary victimization (Ard \& Makadon, 2011; Badenes-Ribera, Frias-Navarro, Bonilla-Campos, Pons-Salvador, \& Monterde-i-Bort, 2015; Hart \& Klein, 2013). In addition, the fear of discrimination related to sexual orientation might make it difficult to seek help from service providers (Ard \& Makadon, 2011; St. Pierre \& Senn, 2010). In fact, prior studies of individuals affected by same-sex IPV have found a low intention to seek help (Chong et al., 2013; St. Pierre \& Senn, 2010; Turell, 1999). Consequently, IPV prevention programs must take into account the specific characteristics of the abuse in same-sex relationships (Brown, 2008). For example, these programs might teach strategies for coping with the discrimination and sexual prejudice that LGBTQ people experience in the context of homophobia. More effective strategies for coping with discrimination and sexual prejudice might buffer the internalizing of heterosexist attitudes and reduce IPV, given the link between internalized homophobia, rumination, and IPV in same-sex relationships 
(Badenes-Ribera et al., 2016; Lewis et al., 2014). Moreover, these primary efforts to prevent IPV might also reduce barriers to disclosure and help seeking among IPV victims (BadenesRibera et al., 2016; Edwards et al., 2015).

Furthermore, changes in public and social policies are required. For example, public institutions would have to dedicate public funds to increasing the availability of specific social services for same-sex partner violence or creating accessible services. As Hart and Klein (2013) point out, there are few comprehensive IPV service programs or social supports offered for gay, bisexual, and transgender people. In addition, the laws on partner violence would have to include partner violence in same-sex couples in order for victims to access the necessary social resources (e.g., economic aid, safe houses), protective measures, and so on (Badenes-Ribera et al., 2015).

We acknowledge some limitations of this meta-analysis that recommend caution in the interpretation of its findings. First, given the low number of studies analyzed in each metaanalysis, the results of our study only represent an initial approach to determining the relationship between internalized homophobia and IPV in same-sex relationships. Moreover, because of the limited number of studies, it was not possible to use moderating variables to study any theoretical explanations for the presence of heterogeneity in the results from primary studies. In addition, there were not enough studies on the relationship between internalized homophobia and IPV victimization to perform a meta-analysis where IPV victimization is broken down by type of violence. This situation reveals that the study of the role of minority stressors in IPV in same-sex relationships is in its infancy. Therefore, it is necessary to carry out more research on the relationship between sexual minority stressors and IPV in same-sex relationships.

In addition, most of the studies included in this metaanalysis were carried out in the United States using a convenience sample taken from LGBTQ communities (predominantly White, with at least some college education), which limits the generalization of these findings to other contexts. Therefore, it is necessary to carry out more research on the role of sexual minority stressors in IPV in same-sex relationships in other societies, cultures, and social contexts, in order to test whether there are differences based on cultural factors.

Another limitation of this meta-analysis is related to the composition of the samples of the studies included. The requirement that IPV had to have taken place in same-sex relationships did not take into account the sexual identities of the participants. Therefore, although most of the samples were made up of participants belonging to sexual minority groups, in some cases $(n=4)$ the samples included a small proportion of heterosexually identified participants: for example, $0.4 \%$ in the study by Balsam and Syzmanski (2005), 2.4\% in the study by Edwards and Sylaska (2013), 9.3\% in the study by Kelley et al. (2014), and $13.9 \%$ in the study by Milletich et al. (2014). However, in the rest of the studies $(n=4)$, the sample was exclusively composed of LGB people. Future studies should evaluate the relationships between internalized homophobia and IPV in same-sex couples among sexual minority individuals and analyze the data in separate groups, for example, based on sexual identity, to explore the role of intersecting identities (Badenes-Ribera et al., 2016; Edwards et al., 2015; Finneran \& Stephenson, 2013; Lewis et al., 2012).

Finally, it is important to keep in mind that all the studies included in the meta-analysis were cross-sectional. Therefore, we cannot make inferences about cause-and-effect relationships. In other words, we cannot know the extent to which internalized homophobia is a true risk factor that precedes IPV perpetration and victimization. In this regard, prospective or longitudinal research might improve our understanding of the way the relationship between sexual minority stressors and IPV actually develops. Such studies would allow us to understand the temporal sequencing of risk and protective factors in IPV victimization, perpetration, and IPV-related outcomes (Edwards et al., 2015; Finneran \& Stephenson, 2013; Lewis et al., 2014). Nevertheless, our study represents the first metaanalysis on the relationship between internalized homophobia and IPV in same-sex relationships, providing a more accurate view of this phenomenon within the limitations mentioned above.

\section{Declaration of Conflicting Interests}

The author(s) declared no potential conflicts of interest with respect to the research, authorship, and/or publication of this article.

\section{Funding}

The author(s) received no financial support for the research, authorship, and/or publication of this article.

\section{References}

An asterisk has been placed next to those references that are included in the meta-analysis.

Ard, K. L., \& Makadon, H. J. (2011). Addressing intimate partner violence in lesbian, gay, bisexual, and transgender patients. Journal of General Internal Medicine, 26, 930-933. doi:10.1007/ s11606-011-1697-6

Badenes-Ribera, L., Bonilla-Campos, A., Frias-Navarro, D., Pons-Salvador, G., \& Monterde-i-Bort, H. (2016). Intimate partner violence in self-identified lesbians: A systematic review of its prevalence and correlates. Trauma, Violence, \& Abuse, 17, 284-297. doi:10. $1177 / 1524838015584363$

Badenes-Ribera, L., Frias-Navarro, D., Bonilla-Campos, A., Pons-Salvador, G., \& Monterde-i-Bort, H. (2015). Intimate partner violence in self-identified lesbians: A meta-analysis of its prevalence. Sexuality Research and Social Policy, 12, 47-59. doi:10.1007/s13178014-0164-7

Balsam, K. F. (2001). Nowhere to hide: Lesbian battering, homophobia, and minority stress. Women and Therapy, 23, 25-38. doi:10. 1300/J015v23n03_03

*Balsam, K. F., \& Szymanski, D. M. (2005). Relationship quality and domestic violence in women's same-sex relationships: The role of minority stress. Psychology of Women Quarterly, 29, 258-269. doi:10.1111/j.1471-6402.2005.00220.x 
*Bartholomew, K., Regan, K. V., Oram, D., \& White, M. A. (2008). Correlates of partner abuse in male same-sex relationships. Violence and Victims, 23, 344-360. doi:10.1891/0886-6708.23.3.344

Bartle, S. E., \& Rosen, K. (1994). Individuation and relationship violence. American Journal of Family Therapy, 22, 222-236. doi:10. 1080/01926189408251316

Bernstein, M., \& Kostelac, C. (2002). Lavender and blue: Attitudes about homosexuality and behavior towards lesbians and gay men among police officers. Journal of Contemporary Criminal Justice, 18, 302-328. doi:10.1177/1043986202018003006

Black, M. C., Basile, K. C., Breiding, M. J., Smith, S. G., Walters, M. L., Merrick, M. T., ... Stevens, M. R. (2011). The National Intimate Partner and Sexual Violence Survey (NISVS): 2010 summary report. Atlanta, GA: National Center for Injury Prevention and Control, Centers for Disease Control and Prevention.

Borenstein, M. J., Hedges, L. V., Higgins, J., \& Rothstein, H. (2009). Introduction to meta-analysis. Chichester, England: Wiley.

Borenstein, M. J., Hedges, L. V., Higgins, J., \& Rothstein, H. (2014). Comprehensive meta-analysis (Version 3). Englewood, NJ: Biostat.

Botella, J., \& Sánchez-Meca, J. (2015). Meta-ananalisis en ciencias sociales y de la salud [Meta-analysis in socials and health sciences]. Madrid, Spain: Síntesis.

Brown, C. (2008). Gender-role implications on same-sex intimate partner abuse. Journal of Family Violence, 23, 457-462. doi:10. 1007/ s10896-008-9172-9

*Carvalho, A. M., Lewis, R. J., Derlega, V. J., Winstead, B. A., \& Viggiano, C. (2011). Internalized sexual minority stressors and same-sex intimate partner violence. Journal of Family Violence, 26, 501-509. doi:10.1007/s10896-011-9384-2

*Chong, E. S. K., Mak, W. W. S., Mabel, M. F., \& Kwong, M. M. F. (2013). Risk and protective factors of same-sex intimate partner violence in Hong Kong. Journal of Interpersonal Violence 28, 1476-1497. doi:10.1177/0886260512468229

Cohen, J. (1988). Statistical power analysis for the behavioral sciences (2nd Ed.). New Jersey, NJ: Lawrence Erlbaum.

DiPlacido, J. (1998). Minority stress among lesbians, gay men, and bisexuals. In G. M. Herek (Ed.), Stigma and sexual orientation (pp. 138-159). Thousand Oaks, CA: Sage.

Duval, S., \& Tweedie, R. (2000). Trim and fill: A simple funnel-plotbased method of testing and adjusting for publication bias in metaanalysis. Biometrics, 56, 455-463.

*Edwards, K. M., \& Sylaska, D. M. (2013). The perpetration of intimate partner violence among LGBTQ college youth: The role of minority stress. Journal of Youth and Adolescence, 42, 1721-1731. doi:10.1007/s10964-012-9880-6

Edwards, K. M., Sylaska, D. M., \& Neal, A. M. (2015). Intimate partner violence among sexual minority populations: A critical review of the literature and agenda for future research. Psychology of Violence, 5, 112-121. doi:10.1037/a0038656

Finneran, C., Chard, A., Sineath, C., Sullivan, P., \& Stephenson, R. (2012). Intimate partner violence and social pressure among gay men in six countries. Western Journal of Emergency Medicine, 13, 260-271. doi:10.5811/westjem.2012.3.11779

Finneran, C., \& Stephenson, R. (2013). Intimate partner violence among men who have sex with men: A systematic review.
Trauma, Violence \& Abuse, 14, 168-185. doi:10.1177/ 1524838012470034

Finneran, C., \& Stephenson, R. (2014). Intimate partner violence, minority stress, and sexual risk-taking among U.S. men who have sex with men. Journal of Homosexuality, 61, 288-306. doi:10. 1080/00918369.2013.839911

Goldberg, N., \& Meyer, I. (2013). Sexual orientation disparities in history of intimate partner violence: Results from the California health interview survey. Journal of Interpersonal Violence, 28, 1109-1118. doi:10.1177/0886260512459384

Greene, K., Causby, V., \& Miller, D. H. (1999). The nature and function of fusion in the dynamics of lesbian relationships. Affilia, 14, 78-97. doi:10.1177/08861099922093527

Hart, B. J., \& Klein, A. R. (2013). Practical implications of current intimate partner violence research for victim advocates and service providers. NCJRS Library collection: U.S. Department of Justice. Retrieved from https:/www.ncjrs.gov/App/Publications/ abstract.aspx?ID=266429

Hatzenbuehler, M. L., Dovidio, J. F., Nolen-Hoeksema, S., \& Phills, C. E. (2009). An implicit measure of anti-gay attitudes: Prospective associations with emotion regulation strategies and psychological distress. Journal of Experimental Social Psychology, 45, 1316-1320. doi:10.1016/j.jesp.2009.08.005

Hellemans, S., Loeys, T., Buysse, A., Dewaele, A., \& De Smet, O. (2015). Intimate partner violence victimization among nonheterosexuals: Prevalence and associations with mental and sexual well-being. Journal of Family Violence, 30, 171-188. doi:10.1007/ s10896-015-9669-y

Herek, G. M., Cogan, J. C., \& Gillis, J. R. (2000). Psychological wellbeing and commitment to lesbian, gay, and bisexual identities. Paper presented in G. M. Herek (Chair), Identity, community, and well-being among lesbians, gay men, and bisexuals, American Psychological Association, Washington, DC.

Herek, G. M., Cogan, J. C., Gillis, J. R., \& Glunt, E. K. (1998). Correlates of internalized homophobia in a community sample of lesbian and gay men. Journal of the Gay and Lesbian Medical Association, 2, 17-25.

Higgins, J. P. T., \& Thompson, S. G. (2002). Quantifying heterogeneity in a meta-analysis. Statistics in Medicine, 21, 1539-1558.

Huedo-Medina, T. B., Sanchez-Meca, J., Marin-Martinez, F., \& Botella, J. (2006). Assessing heterogeneity in meta-analysis: Q statistic or I2 index? Psychological Methods, 11, 193-206. doi: 10.1037/1082-989X.11.2.193

*Kelley, M. L., Milletich, R. J., Lewis, R. J., Winstead, B. A., Barraco, C. L., \& Padilla, M. A. (2014). Predictors of perpetration of men's same-sex partner violence. Violence and Victims, 29, 784-796. doi:10.1891/0886-6708.VV-D-13-00096

Krestan, J., \& Bepko, C. S. (1980). The problem of fusion in the lesbian relationship. Family Process, 19, 277-289. doi:10.1111/j. 15455300.1980 .00277

Lewis, R. J., Milletich, R. J., Kelley, M. L., \& Woody, A. (2012). Minority stress, substance use, and intimate partner violence among sexual minority women. Aggression and Violent Behavior, 17, 247-256. doi:10.1016/j.avb.2012.02.004 
*Lewis, R. J., Milletich, R. J., Derlega, V. J., \& Padilla, M. A. (2014). Sexual minority stressors and psychological aggression in lesbian women's intimate relationships: The mediating roles of rumination and relationship satisfaction. Psychology of Women Quarterly, 38, 535-550. doi:10.1177/0361684313517866

Lockhart, L. L., White, B. W., Causby, V., \& Isaac, A. (1994). Letting out the secret: Violence in lesbian relationships. Journal of Interpersonal Violence, 9, 469-492. doi:10.1177/08862609400 9004003

Mason, T. B., Lewis, R. J., Milletich, R. J., Kelley, M. L., Minifie, J. B., \& Derlega, V. J. (2014). Psychological aggression in lesbian, gay, and bisexual individuals' intimate relationships: A review of prevalence, correlates, and measurement issues. Aggression and Violent Behavior, 19, 219-234. doi:10.1016/j.avb.2014. 04.001

McCandlish, B. M. (1982). Therapeutic issues with lesbian couples. Journal of Homosexuality, 7, 71-78.

McKenry, P. C., Serovich, J. M., Mason, T. L., \& Mosack, K. (2006). Perpetration of gay and lesbian partner violence: A disempowerment perspective. Journal of Family Violence, 21, 233-243. doi: 10.1007/s10896-006-9020-8

Meyer, I. H. (2003). Prejudice, social stress, and mental health in lesbian, gay, and bisexual populations: Conceptual issues and research evidence. Psychological Bulletin, 129, 674-697. doi:10. 1037/0033-2909.129.5.674

Miller, D. H., Greene, K., Causby, V., White, B. W., \& Lockhart, L. L. (2001). Domestic violence in lesbian relationships. Women and Therapy, 23, 107-137. doi:10.1300/J015v23n03_08

*Milletich, R. J., Gumienny, L. A., Kelley, M. L., \& D’Lima, G. M. (2014). Predictors of women's same-sex partner violence perpetration. Journal of Family Violence, 29, 653-664. doi:10.1007/ s10896-014-9620-7

Mohr, J., \& Fassinger, R. (2000). Measuring dimensions of lesbian and gay male experience. Measurement and Evaluation in Counseling and Development, 33, 66-90.

Murphy, C. M., \& Hoover, S. A. (1999). Measuring emotional abuse in dating relationships as a multifactorial construct. Violence and Victims, 14, 39-53.

Murray, C. E., \& Mobley, K. A. (2009). Empirical research about same-sex intimate partner violence: A methodological review. Journal of Homosexuality, 56, 361-368. doi:10.1080/0091 8360902728848

Nolen-Hoeksema, S., Wisen, B. E., \& Lyubominsky, S. (2008). Rethinking rumination. Perspectives on Psychological Science, 3, 400-424. doi:10.1111/j.1745-6924.2008.00088.x

Nowinski, S., \& Bowen, E. (2012). Partner violence against heterosexual and gay men: Prevalence and correlates. Aggression and Violent Behavior, 17, 36-63. doi:10.1016/j.avb.2011.09.005

Pepper, B. I., \& Sand, S. (2015). Internalized homophobia and intimate partner violence in young adult women's same-sex relationships. Journal of Aggression, Maltreatment \& Trauma, 24, 656-673. doi:10.1080/10926771.2015.1049764

Peterman, L. M., \& Dixon, C. G. (2003). Domestic violence between same-sex partners: Implications for counseling. Journal of Counseling and Development, 81, 40-47. doi:10.1002/j.1556-6678. 2003.tb00223.x
Pinel, E. C. (1999). Stigma consciousness: The psychological legacy of social stereotypes. Journal of Personality and Social Psychology, 76, 114-128. doi:10.1037/0022-3514.76.1.114

Renzetti, C. M. (1988). Violence in lesbian relationships: A preliminary analysis of causal factors. Journal of Interpersonal Violence, 3, 381-399. doi:10.1177/088626088003004003

Roberts, J. A. (2006). Developing an explanatory model of the chronicity of psychologically aggressive behavior among coupled gay and bisexual men (Unpublished doctoral dissertation). University of Kentucky, Lexington, KY.

Rostosky, S. S., Riggle, E. D. B., Gray, B. E., \& Hatton, R. L. (2007). Minority stress experiences in committed same-sex couple relationships. Professional Psychology: Research and Practice, 38, 392-400. doi:101037/0735-7028.38.4.392

Sterne, J. A. C., \& Egger, M. (2005). Regression methods to detect publication and other bias in meta-analysis. In H. R. Rothstein, A. J. Sutton, \& M. Borestein (Eds.), Publication bias in meta-analysis: Prevention, assessment and adjustments (pp. 99-100). Chichester, England: Wiley.

Stiles-Shields, C., \& Carroll, R. A. (2015). Same-sex domestic violence: Prevalence, unique aspects, and clinical implications. Journal of Sex \& Marital Therapy, 41, 636-648. doi:10.1080/ 0092623X.2014.958792

St. Pierre, M., \& Senn, C. Y. (2010). External barriers to helpseeking encountered by Canadian gay and lesbian victims of intimate partner abuse: An application of the Barriers model. Violence and Victims, 25, 536-552. doi:10.1891/0886-6708.25. 4.536

Straus, M. A., Hamby, S. L., Boney-McCoy, S., \& Sugarman, D. B. (1996). The revised conflict tactics scales (CTS2). Development and preliminary psychometric data. Journal of Family Issues, 17, 283-316.

Szymanski, D. M., \& Chung, B. (2001). The lesbian internalized homophobia scale: A rational/theoretical approach. Journal of Homosexuality, 41, 37-52. doi:10.1300/J082v41n02_03

Turell, S. C. (1999). Seeking help for same-sex relationship abuses. Journal of Gay \& Lesbian Social Sciences, 10, 35-49.

Wagner, G., Serafini, J., Rabkin, J., Remien, R., \& Williams, J. (1994). Integration of one's religion and homosexuality: A weapon against internalized homophobia? Journal of Homosexuality, 26, 91-110.

Walters, M. L., Chen, J., \& Breiding, M. J. (2013). The National Intimate Partner and Sexual Violence Survey (NISVS): 2010 findings on victimization by sexual orientation. Atlanta, GA: National Center for Injury Prevention and Control, Centers for Disease Control and Prevention.

West, C. M. (2012). Partner abuse in ethnic minority and gay, lesbian, bisexual and transgender populations. Partner Abuse, 3, 336-357. doi:10.1891/1946-6560.3.3.336

\section{Author Biographies}

Laura Badenes-Ribera is a researcher and a professor in the School of Psychology of University of Valencia (Spain). Her research interests are on the methodology of meta-analysis, statistical reform, Psychology and Criminology. She has published articles on statistical 
methods, as well as systematic and meta-analytic reviews on topics focused in intimate partner violence in same-sex relationships. As well, she has published articles on sexual prejudice and discrimination.

Julio Sánchez-Meca is a full professor in the School of Psychology of the University of Murcia (Murcia, Spain). He obtained his $\mathrm{PhD}$ in Psychology in 1985 (University of Murcia) and is teaching statistical methods for the Social and Health Sciences for more than 30 years. His research interests are on the methodology of meta-analysis. He has published a large number of articles on statistical methods in meta-analysis, as well as metaanalytic reviews on topics focused in Psychology and other related Health Sciences. He is member of the Society for Research Synthesis Methodology, the Campbell Collaboration, the Cochrane Collaboration, the European Association of Methodology, and the Spanish Association of Methodology of the Behavioural Sciences.

Claudio Longobardi is a researcher and an assistant professor in the Department of Psychology, University of Turin, Turin, 10123 TO. His main research interest is the child abuse and neglect and developmental psychology in typical and atypical child development. ADDRESS: Department of Psychology, University of Turin, Turin, Via Po 14, 10123 TO, Italy. Email: [claudio.longobardi@unito.it] +39 0116703056 (voice) +390116702061 (fax). 